\title{
Black Lung: Old Disease, New Lessons
}

\author{
Mohammed I. Ranavaya II, BS ${ }^{1}$, Mohammed Ranavaya, MD, JD'1, \\ Natavoot Chongswatdi, MD ${ }^{1}$
}

ABSTRACT

Previous to 2016, cases of progressive massive fibrosis secondary to mining exposure had dwindled and were considered nearly eradicated. However, over 40 new cases were recently discovered in Kentucky, indicating a resurgence of a previously rare disease. We herein report a case of a 44-year-old male underground coal miner from Appalachia with fifteen years coal mining dust exposure who presented with four years of productive cough, dyspnea upon exertion and wheezing for an occupational pneumoconiosis evaluation. Since 2016, he suffered a precipitous decline in lung function consistent with restrictive lung disease and concomitant progression from simple coal workers' pneumoconiosis to progressive massive fibrosis. In particular, his chest x-ray shows classic findings of "angel wings" caused by large fibrotic masses in both lungs. This case, as well as the several other new cases, call attention to the resurgence of PMF and requires examination of the factors contributing to its recent rebound.
Author affiliations are listed at the end of this article.

Correspondence to: Mohammed I. Ranavaya II Marshall University Joan C. Edwards School of Medicine ranavaya3@marshall.edu

\section{KEYWORDS}

Pneumoconiosis, Progressive Massive Fibrosis, Angel Wings, Occupational Lung Disease

\section{CASE PRESENTATION}

Mr. JD, a 44-year-old Caucasian male, presented to our clinic for his second occupational pneumoconiosis claim evaluation in late 2019. He complained of worsening dyspnea on exertion, a chronic cough productive of tan sputum, wheezing, and occasional chest pain since 2016. At that time, he went through his first occupational pulmonary evaluation through our clinic and was found to have simple coal worker's pneumoconiosis. This was based on his chest $x$-ray (CXR) (Figure 1) read by a National Institute for Occupational Safety and Health (NIOSH) certified B-reader and his pulmonary function tests which showed a mild restrictive lung disease (Table 1). Otherwise, he had no other medical conditions at that time.

Because of his younger age, relatively shorter exposure duration, and CXR findings, a recommendation under Federal Black Lung Law (30 CFR 90.201(g)) was made for him to be removed from heavy dust exposure. He was transferred to a surface job as a dispatcher near an area with less dust and higher airflow and provided with a respirator in 2018. He was enrolled in the NIOSH Coal Workers' Health Surveillance Program (CWHSP) ${ }^{1,2}$ and because of rapid progression of his disease, a health hazard evaluation (HHE) from NIOSH began in early 2019. His workplace had air sampling performed by the Mine Safety and Health Administration (MSHA) and demonstrated an exposure of $1.870 \mathrm{mg} / \mathrm{m}^{3}$, nearly three times the excessive concentration value (ECV) of $0.74 \mathrm{mg} / \mathrm{m}^{3}$ and over three times the standard of $0.5 \mathrm{mg} / \mathrm{m}^{3}$.

His occupational history included fifteen years of underground mining experience where he worked as a continuous miner operator. In this job, he operated the continuous mining machines, exposing himself to coal mining dust. He had never smoked but had a twenty-three-year history of chewing snuff.

On examination of his pulmonary system in 2019, he had decreased breath sounds and air movement bilaterally, with prolongation of the expiratory phase and end-expiratory crackles. Otherwise, the physical 


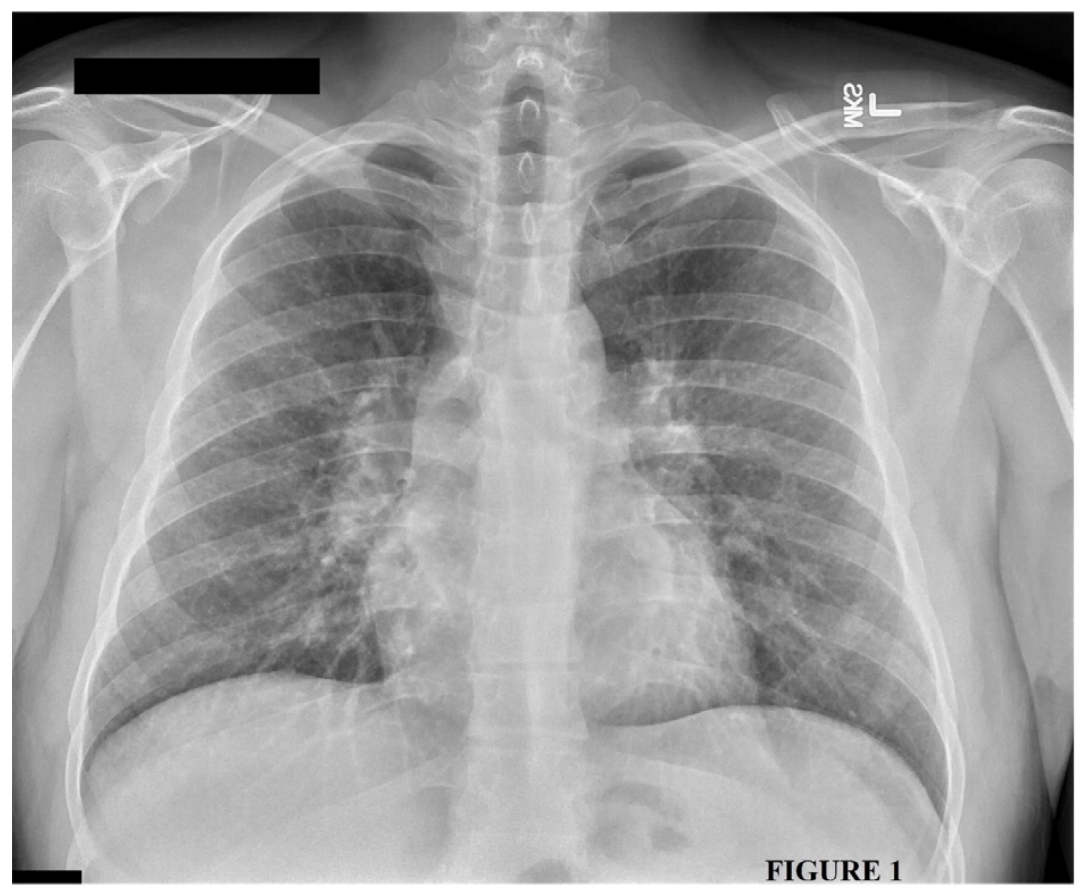

FIGURE 1: Chest x-ray (CXR) taken in December 2016 showing simple coal workers pneumoconiosis.

exam was within normal limits including a cardiac exam with regular rate and rhythm and no digital clubbing or lower extremity edema. Pulmonary function tests were performed which showed severe evaluation of lung transplantation. While a good candidate, he has elected to continue to work at his job in the mines as a dispatcher despite his health condition.

\section{CASE DISCUSSION}

Generally, simple coal worker's pneumoconiosis (CWP) does not result in a severe reduction in lung function. However, about 3-4\% of patients develop a form of an interstitial lung disease called progressive massive fibrosis (PMF), also known as complicated CWP. This can result in total disabling pulmonary dysfunction and develops secondary to coal mining dust exposure. Depending on the seam of coal, coal mining dust contains over fifty different elements including silicates, carbonates, oxides, sulfates, and sulfides. ${ }^{3}$ In particular, silica dust and its related components are the most inflammatory and fibrogenic. Over time, on average 20.7 years 4 , coal mining dust deposits bilaterally throughout the lungs, particularly in the upper regions, leading to the development of confluent

\begin{tabular}{|l|l|l|l|l|l|l|}
\hline Spirometry & \multicolumn{3}{|l|}{ Pre-Bronchodilator } & Post- Bronchodiolator \\
\hline & Pred. & Actual & \%Pred & Pred. & Actual & \%Change \\
\hline FVC (L) & 5.29 & $* 3.72$ & $* 70$ & $* 3.85$ & $* 72$ & +3 \\
\hline FEV1 (L) & 4.20 & $* 2.97$ & $* 70$ & $* 3.23$ & $* 76$ & +8 \\
\hline FEV1/FVC (\%) & 80 & 80 & 90 & 84 & 105 & +5 \\
\hline
\end{tabular}

Table 1: Pulmonary function tests (PFTs) from September 2016 with prebronchodilator studies and post- bronchodilator studies. This study shows good effort. It indicates a mild restrictive defect as reflected by a mild reduction in FVC with concomitant reduction in FEV1 and normal FEV1/FVC ratio.

restrictive lung disease (Table 2). A CXR B-Reading was repeated and it showed the classic "angel wing" opacities of progressive massive fibrosis (Figure 2).

Due to his progressive massive fibrosis (PMF) and a significant reduction in his pulmonary function, he was referred to a major transplant center for areas of fibrosis often seen as large nodules on CXR. As seen in this case, one classic radiographic finding of PMF is the development of "angel wings" (Image 2) which are large confluent areas of fibrosis in the upper lung fields. 
The recent $\mathrm{CDC}$

Bulletin $^{5}$ raises an

alarm that PMF

is a disease on

a resurgence in

Appalachia and

highlights factors

contributing to this

rise. ${ }^{6}$ Once at an all-

time low of $0.33 \%$

in miners with

twenty-five years of

exposure in the late

'90s, the prevalence

has increased to

$3.23 \%$ a nearly
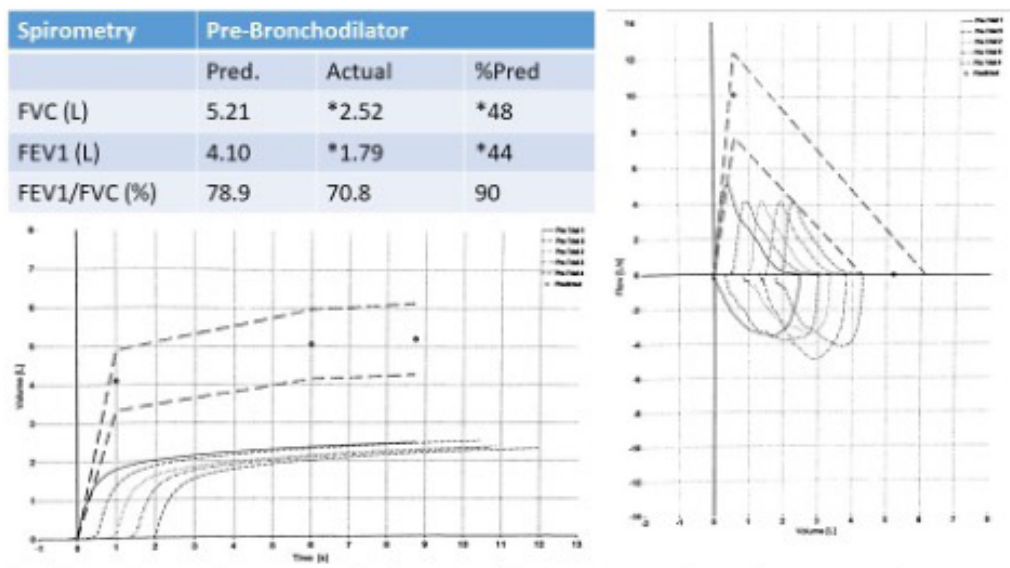

Table 2: Pulmonary function studies (Jan. 2020) showing a normal FEV1/FVC ratio with a precipitous drop in FVC (48\%Pred) and FEV1 (44\%Pred).

tenfold increase. ${ }^{7}$

While the true cause is not readily determinable, as this case demonstrates, the job of continuous miner operator or roof bolter places a miner at greater risk. ${ }^{8}$ These miners are directly at the coal face with high levels of coal mining dust exposure. Additionally, the various coal seams determine the amount of silicates and other components within the coal. Many of the seams that are being accessed now are also thinner containing less coal and more rock such that drilling or cutting through these exposes the miners to respirable minerals. For example, much of the sandstone in eastern Kentucky is made of quartz, a stone known to contain high amounts of respirable silica. ${ }^{5}$

Of note, one other factor that directly contributed to the continued worsening of Mr. JD's lung function was his continued exposure to high levels of respirable coal mining dust despite transferring to a job area with higher ventilation and adequate PPE. As documented by the MSHA after sampling dust from his job site, exposure levels continued to be over three times the excessive concentration value.

\section{CONCLUSION}

Despite near eradication of progressive massive fibrosis as an occupational disease, its resurgence

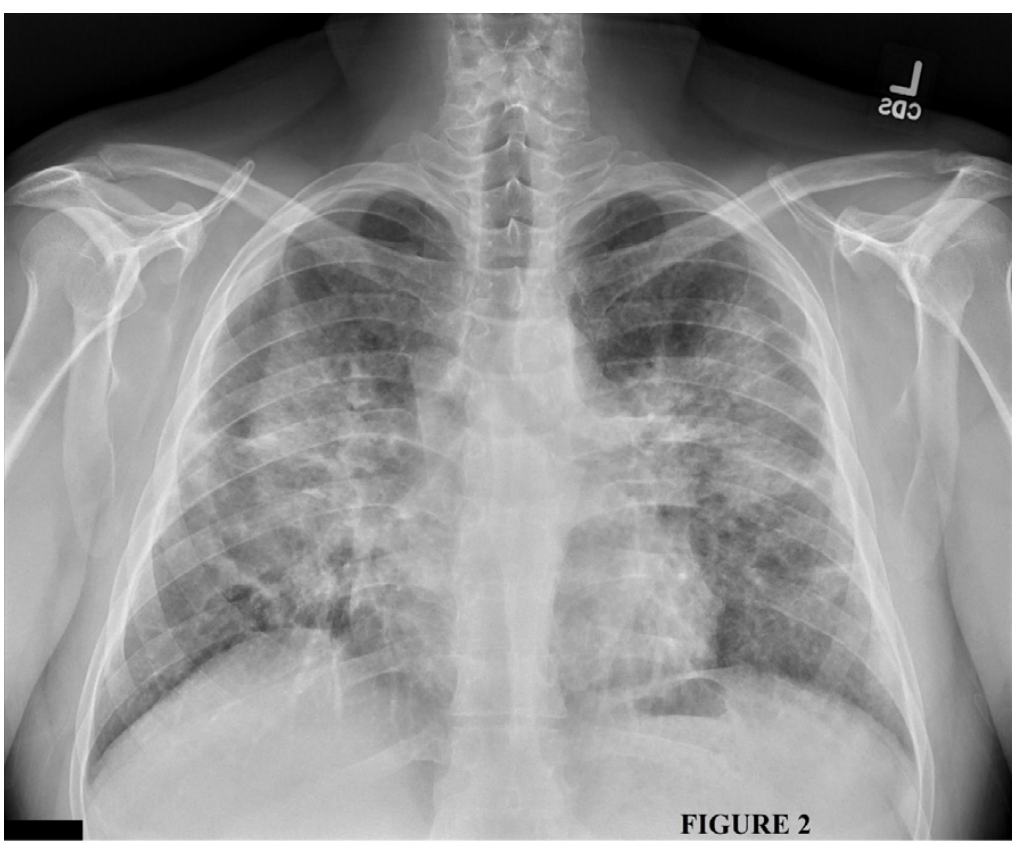

FIGURE 2: Chest $x$-ray (CXR) taken in January 2020 showing progressive massive fibrosis with classic "Angel wing" opacities.

proves it is worth reexamining. Physicians need to be aware of this condition in the community since they will be the first line in detection. As this case demonstrates, it is key to place workers into surveillance programs in a timely fashion; this requires a knowledge of local programs. If these cases are caught, early prevention can be started and disease progression can be mitigated. Although the only curative treatment is a lung transplant, there are 
many symptomatic therapies available that improve the quality of life.

Changes to mining thinner coal seams containing extremely fibrogenic silica dust, access to and appropriate sampling of the worksite coal dust exposure, and location of one's job in the mine are all contributing factors to developing CWP which can progress to PMF. This particular miner's "angel wings" on chest $x$-ray and the fast progression of the disease bring attention to the fact that although this disease has existed since antiquity, there are still new lessons to be learned in its development and spread.

\section{AUTHOR AFFILIATIONS}

1. Marshall University Joan C. Edwards School of Medicine, Huntington, West Virginia

\section{REFERENCES}

1. Federal Coal Mine Health and Safety Act of 1969. Washington; 1969.

2. Federal Mine Safety and Health Amendments Act of 1977. October 3, 1977. Washington, DC; 1977.

3. Silica, Some Silicates, Coal Dust and Para-Aramid Fibrils. Lyon, France: IARC; 1997. Available from: https://www.ncbi.nlm.nih.gov/books/ NBK410045/

4. Laney AS, Blackley DJ, Halldin CN. Radiographic disease progression in contemporary US coal miners with progressive massive fibrosis. Occup Environ Med. 2017;74(7):517-520.

5. Blackley DJ, Crum JB, Halldin CN, Storey E, Laney AS. Resurgence of progressive massive fibrosis in coal miners - Eastern Kentucky. MMWR Morbidity and Mortality Weekly Report. 2016;65(49):13851389.

6. Reynolds LE, Blackley DJ, Colinet JF et al. Work practices and respiratory health status of Appalachian coal miners with progressive massive fibrosis. Journal of Occupational and Environmental Medicine. 2018;60(11).

7. Blackley DJ, Halldin CN, Laney AS. Resurgence of a debilitating and entirely preventable respiratory disease among working coal miners. Am J Respir Crit Care Med. 2014;190(6):708-709.

8. Huang Y-CT, Ghio AJ, Maier LA. A clinical guide to occupational and environmental lung diseases. Totowa, NJ: Humana Press; 2012. 
